\title{
BMJ Open Acceptability of a mHealth strategy for hypertension management in a low- income and middle-income country setting: a formative qualitative study among patients and healthcare providers
}

\author{
Buna Bhandari (D) , ${ }^{1,2}$ Aletta E Schutte (D) , ${ }^{1,3}$ Rohan Jayasuriya (D) , \\ Abhinav Vaidya (1) , ${ }^{4}$ Madhusudan Subedi, ${ }^{5}$ Padmanesan Narasimhan ${ }^{1}$
}

To cite: Bhandari B,

Schutte AE, Jayasuriya $R$, et al. Acceptability of a mHealth strategy for hypertension management in a low-income and middle-income country setting: a formative qualitative study among patients and healthcare providers. BMJ Open 2021;11:e052986. doi:10.1136/ bmjopen-2021-052986

- Prepublication history and additional supplemental material for this paper are available online. To view these files, please visit the journal online (http://dx.doi.org/10.1136/ bmjopen-2021-052986).

Received 30 April 2021 Accepted 03 November 2021

Check for updates

(C) Author(s) (or their employer(s)) 2021. Re-use permitted under CC BY-NC. No commercial re-use. See rights and permissions. Published by BMJ.

For numbered affiliations see end of article.

Correspondence to

Buna Bhandari;

buna.bhandari@gmail.com

\section{ABSTRACT}

Background Understanding contextual needs and preferences is important for a successful design and effective outcome of a mHealth strategy.

Objectives This formative study aimed to explore the perspectives of patients and providers on the acceptability of a mHealth (text message) strategy and elicit preferred features of a mHealth strategy for hypertension management.

Design A qualitative study was conducted using in-depth interviews and focus group discussions guided by the technology acceptance model.

Setting The study was conducted at primary healthcare facilities and at a tertiary level referral hospital in Kathmandu, Nepal.

Participants A total of 61 participants, patients with hypertension ( $n=41)$, their family members $(n=5)$, healthcare workers $(n=11)$ and key informants $(n=4)$ were included. We purposively recruited patients with hypertension aged 30-70 who attended the selected healthcare facilities to obtain maximum variation based on their age, sex and literacy.

Results The respondents perceived the mHealth strategy to be useful as it would reinforce medication compliance and behaviour change. Participants valued the trustworthiness of information from health authorities that could be delivered privately. Some implementation challenges were identified including a lack of technical manpower, resources for software development, gaps in recording a patient's essential information and digital illiteracy. Solutions proposed were having systemlevel preparedness for recording the patient's details, establishing a separate technical department in the hospital and involving a family member to assist illiterate/ elderly patients. In addition, participants preferred text messages in the local language, containing comprehensive contextual content (disease, treatment, cultural foods and misconceptions) delivered at regular intervals (2-3 times/ week) preferably in the morning or evening.

Conclusions We found that a simple text messaging strategy was acceptable for hypertension management in this low/middle-income country setting. However, meticulous planning must address the needs of a diverse

\section{STRENGTHS AND LIMITATIONS OF THIS STUDY}

$\Rightarrow$ This formative study is the first conducted in Nepal that explored the acceptability of a mobile phone text messaging strategy targeting patients with hypertension guided by a technology acceptance model.

$\Rightarrow$ The strength of the study was the inclusion of diverse stakeholders such as patients, providers, family members and policy-makers at different levels of the healthcare system.

$\Rightarrow$ This study was conducted in urban and semiurban parts of the country, limiting the transferability of findings to rural and disadvantaged areas.

range of participants to ensure the mHealth strategy is acceptable to wider groups.

\section{INTRODUCTION}

Hypertension, a major cardiovascular disease (CVD) risk factor, is an emerging public health challenge particularly affecting low/middleincome countries (LMICs). ${ }^{1}{ }^{2}$ Although highly effective and affordable medications are widely available, a major challenge in LMICs remains abysmal hypertension control of less than $50 \% .^{3}$ Nepal is no exception to this, with $57 \%$ of patients remaining undiagnosed in the community due to the often asymptomatic nature of hypertension. ${ }^{4}$ In addition, among those who are diagnosed, only $35 \%-45 \%$ of the hypertensive patients have controlled blood pressure, ${ }^{56}$ leading to high mortality and morbidity. ${ }^{7}$

The Global Burden of Disease Study 2019 recommends that countries invest in costeffective public health interventions to improve blood pressure control and prevent premature deaths from hypertension and consequent CVD. ${ }^{8}$ Globally, a wide range of 
non-pharmacological interventions are implemented to improve blood pressure control, such as self-monitoring of blood pressure, ${ }^{9}$ educational interventions focused on patients, ${ }^{10}$ health professional-led care (nurse, pharmacist, community health workers) ${ }^{11}$; as well as appointment reminders. ${ }^{12}$ However, delivery of these interventions is hindered by inadequate communication between patients and providers ${ }^{13}$ primarily due to poor clinician-to-patient ratios in low-resource settings. ${ }^{14}$

Mobile health or mHealth interventions use mobile devices such as mobile phones, patient monitoring devices, personal digital assistants and other wireless devices to support medical or public health practice. ${ }^{15}$ In low-resource settings, mobile phones are a promising tool to improve healthcare access and coverage. ${ }^{16} 17$ Mobile technologies offer a simple and effective mode of communication, enabling the patient to self-manage hypertension through tailored feedback. ${ }^{18}{ }^{19}$ Included in self-management, a text message is an appropriate mode to guide behaviour interventions, ${ }^{20}$ and although simple, has many advantages over other mobile applications and computer interventions, especially in lowresource settings or remote areas with limited internet access. ${ }^{20} 21$

The Nepal Telecom Authority estimates that there are 38.21 million mobile service users in Nepal. ${ }^{22}$ Despite this penetration of mobile services to the population, only a few pilot projects have used mobile services for nutrition counselling and maternal and child health services $^{23} 24$ and only a handful of initiatives for noncommunicable disease (NCD) management targeting community health workers. ${ }^{25}$ There is immense potential to use mobile services to bridge the communication gap between providers and patients for hypertension management in Nepal. However, it is essential to understand its acceptability among target populations and consider country-specific needs to develop an effective mHealth strategy. ${ }^{26}$ This formative study aimed to explore different stakeholder's perceptions on the use of mHealth (text messages) to capture multiple level perspectives guided by the technology acceptance (TAM) model $^{27}$ and elicit their preferred features of mHealth (text messages) strategies for hypertension management in Nepal.

\section{METHODS}

Qualitative research was conducted to explore the perspectives of the study participants on the potential use of a mHealth (text message) strategy for patients with hypertension. This study was conducted at primary healthcare facilities (one primary healthcare centre and five health posts) of Kageswori Manahara municipality and at a tertiary level referral Hospital in Kathmandu, Nepal (Kathmandu Medical College and Teaching Hospital), to explore the perspectives of people of different healthcare levels.

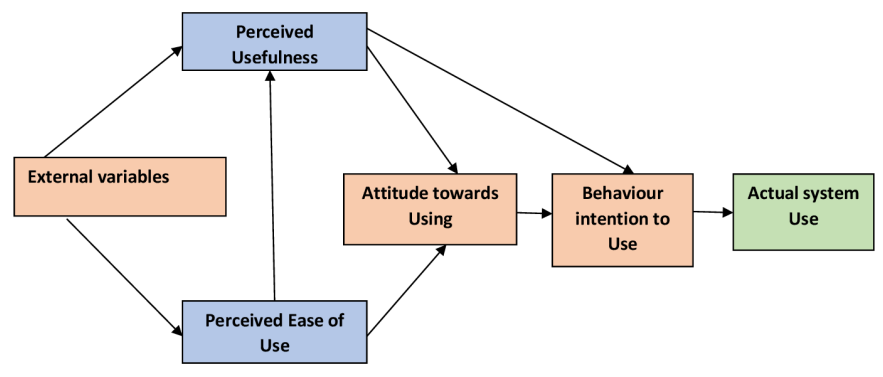

Figure 1 Technology acceptance model. (Davis,1989)

\section{Theoretical model informing the study}

Our study used the TAM model developed by Davis ${ }^{27}$ as an overarching model to guide the analysis to assess the acceptability of the proposed mHealth strategy (figure 1). This model considers two main beliefs: perceived usefulness and perceived ease of use as the main factors for an individual's acceptance of the technology. Perceived usefulness is when users believe that using technology will enhance their job performance. Perceived ease of use is a user's belief that technology is free of effort, which is influenced by external factors. ${ }^{27}$ We focused on these factors in our study. The TAM model assumes that there is a strong relationship between a person's intention to use and a person's actual use of technology. ${ }^{28}$ This model is valid, robust and widely used to understand human behaviour in acceptance of technology. ${ }^{28-32}$ We have used this model for informing our analysis considering its applicability based on our objectives .

\section{Study populations and recruitment}

We included patients with hypertension aged 30-70 who attended the selected healthcare facilities from March to July 2018. We excluded patients with complicated hypertension with severe multimorbidity requiring immediate care at tertiary-level hospitals, which would limit their ability to participate in the study. Participants with severe mental and physical disabilities and pregnant/postpartum women were excluded from the study. However, we included participants with comorbidities who were not serious. We have included the different groups of patients (based on age, sex, literacy), their family members, healthcare workers (HCWs) from both levels of care, and key informants (KI) to capture the multiple perspectives for validating the data through data source triangulation. ${ }^{33}$ Perspectives from patients and family members helped in understanding patient community-level perspectives whereas KI and HCWs perspectives provided an opportunity to understand the system-level factors for the contextual design of the mHealth strategy. The details of the study participants and the recruitment process have been described previously ${ }^{13}$ and presented briefly in online supplemental file 1 .

\section{Data collection methods}

We collected data using in-depth interviews (IDIs) and focus group discussions (FGDs) to ensure rigour through methodological triangulation. ${ }^{33}$ IDIs provide an 
opportunity to explore rich personal experiences and perspectives on the topic. ${ }^{34}$ However, FGD elicit data from a group of participants where they could hear each other perspectives and comments additionally which they may not have expressed in the IDIs. ${ }^{35}$ IDIs and FGDs were conducted using a semistructured interview guide. The interview guide contained the questions mainly on perspectives on using the mHealth intervention, its advantages, challenges and their preference on the contents and frequency of the text messages (online supplemental file 2). Prior to giving consent to take part in the study, participants were informed of the objectives of the study, conceptual mHealth (TEXT4BP) study, and about the interviewer. The first author BB (female, PhD fellow), a native language speaker trained in qualitative research methods, conducted all the IDIs in the Nepali language in a suitable private place out patient department (OPD) of health facilities or privately at the home of the participants without the presence of family members). Interview observation notes for non-verbal cues and audio recordings captured the interview data, which lasted for about 35-60 min. A total of 25 IDIs among hypertensive patients, 5 IDIs among family members, 11 IDIs among HCWs and 4 IDIs among KI were conducted. Two FGDs were also conducted using the FGD guides among 16 (8 participants in each FGD) diverse hypertensive patients at a private OPD room with no additional person presented at the tertiary level. The FGDs were facilitated by the first author in the Nepali language, audio recorded and each FGD lasted for 60-90 min. We decided the number of participants for FGDs based on the standard recommendations for FGDs and patient availability. ${ }^{36}$ The number of IDIs was decided based on the number of diverse group representation (by age, sex, literacy) until reaching a saturation point of information achieved at both levels of healthcare. To decide on the saturation point, the interviewer prepared the summary after each interview to look for any new information coming from IDIs (table 1 ).

\section{Data analysis}

All audio recorded FGDs and IDIs with the research participants were transcribed in the local language (Nepali) by the first author and a qualified transcriber. The transcripts were checked against the audio recordings for ensuring accuracy, and pseudonyms were applied to deidentify participants. The transcripts and observation notes were translated into English by the researcher and a qualified translator. Translation reliability and accuracy were checked in a random sample of transcripts by back-translation of the transcripts to compare with the original script in local language by the first author (BB). Transcripts were not shared with the participants; however, the interviewer summarised the main information at the end of the interview to obtain participant validation. ${ }^{37}$ NVivo V.12 software $^{38}$ was used for data management. The first author coded all the transcripts. Data analysis was informed by the TAM model and overarching aim of the study. This study used this model to understand the perceived usefulness, perceived ease of use and perceived challenges of using text messages as a behaviour change strategy. We followed the thematic analysis process proposed by Braun and Clarke. ${ }^{39}$ This method of analysis involves familiarisation with the transcribed data by reading and rereading, generating codes, searching for and reviewing themes, defining and naming themes and finalising the analysis. The codes and themes were discussed with the coauthor (PN) and agreed on between investigators ( $\mathrm{BB}$ and $\mathrm{PN}$ ). The subthemes generated from the transcripts were mapped under the overarching theme (I-III) of the TAM model and other themes (V-VI) generated based on the objectives of the study as presented in the Result section. We followed the

Table 1 Total number of study participants for in-depth interviews (IDIs) and focus group discussions (FGDs) included from the primary and tertiary level.

\begin{tabular}{|c|c|c|c|}
\hline Participant group & Primary healthcare level (PL) & Tertiary healthcare level & Total \\
\hline Patients with hypertension & 13-IDIs & 12-IDIs & 25 \\
\hline Patients with hypertension & NA & 2 FGD (8 in each)* & 16 \\
\hline $\begin{array}{l}\text { Family members of patients with } \\
\text { hypertension }\end{array}$ & $3-I D I s$ & 2-IDIs & 5 \\
\hline Key informants & \multicolumn{2}{|c|}{$\begin{array}{l}\text { 4-IDIs } \\
\text { NCDs policy-maker-1 } \\
\text { NCDs programme focal person at DoHs, MoHP-2 } \\
\text { NCDs researcher } 1\end{array}$} & 4 \\
\hline
\end{tabular}

\section{Total 61}

${ }^{*}$ Due to low patient flow at PL, FGDs could only be conducted at the tertiary level.

DoHs MoHP, Department of Health Services, Ministry of Health and Population; NCDs, non-communicable diseases. 
Table 2 Sociodemographic profile of the study participants of in-depth interviews and focus group discussions (hypertensive patients)

\begin{tabular}{|c|c|c|c|}
\hline \multirow[b]{2}{*}{ Characteristics } & \multirow[b]{2}{*}{ Categories } & \multicolumn{2}{|c|}{ Hypertensive patients $(\mathrm{N}=41)$} \\
\hline & & Frequency & Percentage \\
\hline \multirow[t]{5}{*}{ Age (years) } & $30-40$ & 10 & 24.4 \\
\hline & $40-50$ & 11 & 26.8 \\
\hline & $50-60$ & 12 & 29.3 \\
\hline & $60-70$ & 8 & 19.5 \\
\hline & Mean age $\pm S D$ & $48.17 \pm 10.78$ & \\
\hline \multirow[t]{2}{*}{ Sex } & Female & 21 & 51.2 \\
\hline & Male & 20 & 48.8 \\
\hline \multirow[t]{2}{*}{ Literate } & Yes & 27 & 65.8 \\
\hline & No & 14 & 34.2 \\
\hline \multirow[t]{2}{*}{ Employment } & Yes & 29 & 70.7 \\
\hline & No & 12 & 29.3 \\
\hline \multirow[t]{3}{*}{ Duration of diagnosis of hypertension } & Less than a year & 5 & 12.2 \\
\hline & $1-5$ years & 22 & 53.6 \\
\hline & More than 5 years & 14 & 34.2 \\
\hline
\end{tabular}

Consolidated criteria for Reporting Qualitative research 32-item checklist ${ }^{40}$ to ensure reporting consistency (online supplemental file 3).

\section{Patient and public involvement}

This research was conducted without patient or public involvement. Participants were not invited to comment on the study design or contribute to the research write up and dissemination.

\section{RESULTS}

Most of the hypertensive participants (29\%) were between the ages of 50-60 years with a mean age of 48 years, women $(51 \%)$, literate $(65 \%)$ and employed $(70 \%)$. Of them, $88 \%$ had been diagnosed more than 1 year prior to study and $34 \%$ were diagnosed more than 5 years prior to the study (table 2)

Our study revealed three broad themes (I-III) of acceptability under the TAM model and other two themes (IV-V) as suggested solutions, and preferred features of the mHealth strategy. All the themes, subthemes of study and supporting verbatim are presented in table 3 .

\section{Themes mapped under TAM model}

Perceived usefulness

The main subthemes under perceived usefulness of TAM model are as follows:

\section{Acceptable and require less resources}

Study participants reported that a simple text message would be acceptable in the study settings due to the ubiquity of mobile phones.
Participants mentioned that mobile phones are popular. They also expressed their interest and readiness to participate in such a programme. "If you send us short messaage service (SMS), we are ready to use this." (P03: 50-55 Y,F, TL)

HCWs also confirmed that mobile phones are widely accessible, even in rural areas. Some stated that getting messages on their mobile phone would be very handy and save time spent for travel to the health centre for getting information about the disease and its treatment. The KI examined mHealth from a programme perspective. Participants identified SMS might require less resources as it can be sent to many people at the same time (bulk SMS) with limited investment.

\section{Reinforce behaviour change}

HCWs mentioned that text messages could act as a reminder to take medication on time and reinforce recommended behaviour changes such as physical activity.

Participants stated that using a text message strategy might meet their unmet needs to receive specific information to reinforce behaviour change such as how much salt is recommended for blood pressure control.

If specific information (such as this much salt is allowed) will be sent for us, definitely it would help for changing our habits. (FGD 02: 50-55 Y, F, TL)

\section{Can provide reliable information}

Some participants reported that they could search for unlimited information from the internet on their mobile by themselves. However, the authenticity and relevance 
Table 3 Themes and subthemes generated on the perception of using a mHealth (text message) strategy

\section{Themes based on TAM model on acceptability}

Perceived usefulness
Subthemes

Acceptable and require These days, mobile(phone) is widely available and easy to use for many people. If less resources

\section{Supporting verbatim} (P021: M, 40-45 Y, PL) It is also a cost-effective programme. We can send one SMS to millions of people in a short period. It will increase coverage among the patients and will be more effective. (KIIO2)

Reinforce behaviour "The patients should at least be notified on their mobile phones to take their medicine on change time. Then, the patient would realise and be motivated to follow that." (HCW 02, PL)

Can provide reliable information

"If messages are sent by you and others like you (health professional), I will happily accept it thinking that doctor with whom I meet at the hospital ... sent this message." (P013: 45-50 Y, PL)

Deliver information "If I get information on my mobile, then it might help to improve my blood pressure. If I privately go to the health centre, there would be lots of people ... I feel shame to say myself ill in front of other people. I have not shared with friends, as well." (P014: 35-40 Y, M, TL)

Perceived ease of use User friendly I think it will work and be feasible because majority of the people own mobile phone, can very easily see the information in mobile without any difficulties and there is no need to have expensive smartphone for simple SMS. (P20: M, 50-55Y, PL)

Local language

The SMS language should be simple and easy to understand for us. Nepali is the most common language out here and people can easily read that. (P015: 30-35Y, M, TL)

Perceived challenges-

Mobile phone illiteracy external factors

Technical constraints understand whatever things come into our mobile.... is not it? (FGD01; 60-65Y, F, TL)

"No. No. How can we manage those mobile services? It will be challenging to implement. It needs a considerable amount of budget, though the concept is excellent." (HCW 03: PL)

\begin{tabular}{ll}
$\begin{array}{l}\text { Themes under other } \\
\text { objectives of study }\end{array}$ & Subthemes \\
\hline $\begin{array}{l}\text { Perceived solutions for } \\
\text { overcoming the challenges }\end{array}$ & $\begin{array}{l}\text { System-level } \\
\text { preparedness }\end{array}$
\end{tabular}

\section{Supporting verbatim}

The hospital must also have a record of the detailed list of OPD patients diagnosed with hypertension. Proper record-keeping is essential. (HCW 09: TL)

"For such project, we need some mobile centres/department, or some technical manpower then only we can implement it." (KII 03)

Alternatives strategies "These days though mother/father is illiterate, there will be son, daughter and for illiterate

grandchildren who are educated. If we could send the message to the family member of the illiterate patients, they will get the information. (HCW 07: PL)

Preferred features of the mHealth strategy

Comprehensive contextual contents

Is blood pressure (BP) controlled after taking bitter herbs (chirauto) only or should we go for acupuncture or not...some people say that there is a person who press in the hand and pressure will be fine, so should we follow that or not ?- it should be send in messages. (P08: 50-60 Y F, PL)

It should include all the information regarding what type of diet should we take and what should be avoided. Like messages regarding patient should take less salty and oily food. (P012: 45-50 Y, F, PL)

Reasonable frequency "I feel like if it can be sent once or twice a week, then it will be kept in touch also. If we and timing of $\quad$ send them daily, then they might delete it. (laughs)." (HCW 05, TL)

messages

status. This was the case with younger patients, who did not want their illness divulged to people they associate with.

Overall, there was no reported difference in usefulness based on the gender and level of healthcare. However, the advantage of getting messages privately was expressed mainly by the younger participants, not by the older age groups.

\section{Perceived ease of use}

User friendly

Participants stated that the text messages are a simple and easy strategy as text messages do not require advanced privately. They valued personal text messages sent on their mobile to maintain privacy regarding their hypertension 
technical skills to operate. Participants preferred receiving messages in a simple, clear and concise format. They added that if SMS is designed in an understandable format, it could be effective in the study setting.

It will be effective. These days, even the lay man (najjanne), can use simple messaging. (P10: 45-50Y, F, TL)

\section{Local language}

Study participants stated that it would be easiest to read and understand if the messages would be sent in the Nepali language. If designed in a local language, people with low literacy could also use the mHealth intervention for behaviour modification.

Yes, she (patient) could read it if it is sent in Nepali. If sent in English, even I cannot read it. But we both can read in Nepali. (FM03 of 40-45Y, F, PL)

The ease of use was expressed mostly by the literate group of participants. Older and illiterate participants suggested designing simple text messages in the local language.

\section{Perceived challenges-external factors}

Many participants also identified obstacles to implement the mHealth strategy in the study settings.

\section{Mobile phone illiteracy}

Some participants raised concerns about general literacy and digital literacy of patients in reading the SMS even though messages would be sent in the local (Nepali) language. They reported that it could be difficult for those who have low digital literacy skills, for example, who do not know how to open, read or send a text message.

Further, an older participant mentioned that "No, I only know how to call. I have a simple mobile. I do not know how to open and read the messages." (P017: 65-70Y, $\mathrm{M}, \mathrm{PL}$ )

HCWs added that such a programme could be more effective in urban areas and are most accessible to the young generation. The participants expressed that age and illiteracy may influence the ability to read text messages.

\section{Technical constraints}

HCWs were cautious, highlighting the need for resources to implement such a programme in Nepal. They expressed concern about resources such as the technical workforce and funding requirements for software development and SMS delivery, including commitment from the authorised bodies in the hospital. Some HCWs also raised the issue of health system preparedness to implement such programmes due to costs and a limited technical workforce.

Many HCWs identified challenges, such as not having an appropriate recording system for hypertensive patient's details in the hospitals to locate and trace them in the community. They argued that text messaging would be almost impossible in public hospitals where doctors have a high workload, limiting their ability to record the patients' details, such as their phone number. One HCW stated that "There is not even a good record-keeping system here in our hospital, and no one is going to record as we don't have time." (HCW 08: TL)

The system level technical challenges were expressed by both levels of healthcare; mostly by the HCWs and KI. No such issues were reported by the hypertensive patients.

\section{Themes based on other objectives of the study} Perceived solutions

In the context of resource constraints, participants recommended some solutions to create the desired outcome of mHealth strategy.

\section{System-level preparedness}

HCWs emphasised a proper record-keeping system, which would help in tracing the hypertensive patients to send SMSs.

However, they emphasised the need for government commitments for such programmes, such as establishing a separate department to monitor the programme.

KI highlighted the need for system-level preparedness by extensive planning, budgeting and mobile phone text messaging software development. They stated that multisectoral collaboration and commitments will be needed to implement the mHealth programme effectively.

\section{Alternative strategies for illiterate groups}

Participants suggested including a family member of illiterate patients when sending messages. They mentioned that every household should have at least one literate person, and family members were ready to support illiterate relatives and parents.

They stated that "For Illiterate people like my mother, it has to be sent to the member of the family like me. As a son, I must take care of her" (FM 02 of 60-65 Y, F, PL). Furthermore, video/voice messages, symbolic pictures or cartoons were recommended by HCWs for the illiterate groups.

I think the video is more effective than a text message as it has both audio/visual features (P014: 35-40Y, M, TL)

However, some participants raised concerns about the family member's relationship with patients and their availability and the feasibility of using video messaging in a resource-constrained setting like Nepal. These concerns were especially prominent at the primary level where smartphones, internet and MMS facilities are limited and less available.

\section{Preferred features of the mHealth (text message) strategy}

In each IDI and FGD, answers to questions regarding the need and preference of participants to inform the content and delivery of text messages were analysed. 


\section{Comprehensive contextual contents}

Participants expressed various misconceptions prevalent in the study setting regarding hypertension and its treatment. Participants preferred getting context-specific messages targeting misconceptions about hypertension treatments such as use of locally available herbs: aloe vera juice, bitter juice (Chirauto), barley sprout juice (Jamara) and so on. Similarly, participants suggested including messages targeting the foods prepared during festivals in Nepal which are high in fat and salt content.

Patients says that "yesterday I attended a festival. After eating high salt food and meat, I am getting headache, so I came here for check-up." So, I think you should send information about diet as well. (HCW 04: TL)

For lifestyle modification, some participants stated that it would be good to receive information about physical activity and culturally appropriate dietary factors. "What kinds of exercise should be done, how much... amount... duration... Time. "KI also added that patients should get all the messages on pharmacological and nonpharmacological measures for controlling their blood pressure.

Overall, content preferences included information about hypertension and its treatment, dietary factors (local foods), medication, side effects, physical activities and reminder for medication.

\section{Reasonable frequency and timing of text messages}

Participants also stated that text messages should be delivered with reasonable frequency and timing. Study participants preferred receiving 2-3 reminder messages per week for taking medications or about specific behaviours. Overall, participants agreed that daily messaging would be too often and monthly messaging would be insufficient.

If you send in the interval of 2-3 days, then then we might see that. (P018: 40-45 Y: M, PL)

Most of them preferred messages to be delivered in the morning or evening. Participants mentioned that if the timing of the message matched with the time of taking their medicine, then it would be more effective "Usually people take medicine in the morning so, that would be a good time." (P05:45-50, F, PL) Another participant also added. "for women.... evening time would be good as we will be busy in household works during morning." (FGD 05: 30-35 Y; F, TL)

Overall content preferences were not different based on the gender, age and level of care. However, female participants expressed greater preference to receive messages in the evening time.

\section{DISCUSSION}

This study explored the perspectives of patients and providers on the acceptability of mHealth (mobile phone text messages) strategy for patients with hypertension in
Nepal. Overall, participants were receptive towards the text message-based intervention with some contextual recommendations. This study found that simple mobile phone text messages could be useful in this setting due to the ubiquitous use of mobile phones. Studies at the primary level ${ }^{26}$ and in rural parts of India ${ }^{41}$ have reported similar findings of mHealth being a ubiquitous and acceptable tool for managing CVDs and supporting healthcare. KI involved in implementing the national NCDs programme and policy in Nepal identified the lowresource requirements of SMS as potentially useful for such interventions. The WHO's Global Observatory for eHealth (GOe) also argues that SMS is an easy method to disseminate targeted health information at a low cost. ${ }^{15}$ Text messages can be sent in bulk to multiple users simultaneously, are cheap, and do not require advanced skills on the part of the health service or the patient. ${ }^{16}$ However, cost-effectiveness analysis is an area for future research in this setting.

Our study found behaviour reinforcement/modification to be another potential use of mHealth. In chronic diseases such as hypertension where medication should be taken daily, SMS reminders can increase medication adherence. $^{42} 43$ Additionally, WHO GOe stated that SMS was the preferred method for treatment compliance measures worldwide. ${ }^{15}$ Non-disclosure issues due to the stigma attached to hypertension were reported, especially by young people in Nepal in an earlier study. ${ }^{13}$ The importance of receiving messages privately on mobile phones was stressed by our respondents. It has not been reported for NCD previously, but these were mostly reported in studies of HIV/AIDS. ${ }^{44}$ Overall, there was a consensus on the value of text messaging in getting information privately (in confidence) to hypertensive patients by all the stakeholder groups. However, our study participants did not mention concerns about data security, an increasingly important factor in designing mHealth strategies.

Our participants found the text message strategy easy to operate and not requiring advanced technical skills. Participants preferred to have messages in the local Nepali language for the ease of use of broader groups. We were able to identify implementation challenges that were similar to other resource-limited settings as well as unique to Nepal. Difficulty in reading text messages (even in the local language), a language and literacy barrier including digital literacy in reading the text messages were reported in this study, similar to South Indian studies. ${ }^{26} 44$ In Nepal, though mobile phone penetration is high, digital literacy is only reported as $31 \% .^{45}$ In this context, alternative solutions identified by stakeholders were the inclusion of family members of illiterate/older people and sending video or symbol-based messages.

While there was enthusiasm to use mHealth, HCWs and KI expressed concerns about the lack of resources and technical issues that could be an impediment. A key concern was that implementing a new mHealth (SMS) system in the hospital might require extra technical manpower for software development, generating a need for a separate 
technical department. The immaturity of health information systems in hospitals and gaps in recording essential information was also identified as a potential limitation. Similar issues have been reported from rural India as a barrier to the continuity of care and follow-up with hypertensive patients. ${ }^{46}$ These findings are corroborated by other studies in Kenya ${ }^{47}$ and Bangladesh. ${ }^{48}$ The WHO has also stated that unclear mHealth policies and underdeveloped infrastructure are the most common barriers to adopting mHealth in LMICs settings. ${ }^{15}$ In our study, it was explicitly stated that a reliable and peer-reviewed source of information is required. An SMS originating from a public or private health centre will be trusted by individuals as they would be considered reliable. It is therefore imperative to establish the trustworthiness of the information for the desired behaviour modification. ${ }^{49}$ The key recommendation was to have government commitment and multisectoral collaboration and coordination with the health system to address the structural barriers to use advanced technology. These aspects should be carefully considered while designing any mHealth strategy for its sustainability.

\section{Implications for mHealth design and future research}

This study contributes to a small but growing body of evidence that mHealth could be an acceptable strategy in LMIC settings if designed based on the local context and needs. ${ }^{51}$ Our study participants highlighted their interest in getting messages clarifying the misconceptions regarding the use of local herbs for treatment of high blood pressure and targeting cultural food practices. The findings of this formative research informed the next phase of the TEXT4BP study, tested using a randomised controlled trial design. ${ }^{52}$ Information on the contents of SMS texts, their frequency and timing of the messages may be of value in similar resource-limited settings. In Nepal, there are very few studies on mHealth. The need for the evidence-based use of modern technology in health service delivery is emphasised in the Nepal Health Sector Strategy 2015-2020 ${ }^{53}$ This study's findings represent a crucial contribution for designing evidence-based mHealth strategies in Nepal.

The COBRA-BPS (Control of Blood Pressure and Risk Attenuation-Bangladesh, Pakistan, and Sri Lanka) study in Pakistan, Bangladesh and Sri Lanka ${ }^{54}$ provided promising evidence in improving blood pressure control. However, their main intervention was based on mobilising community HCWs and training physicians. In Nepal, due to the scarce human resources and overburdened Female Community Health Volunteers, it is important to develop and test interventions that would not burden the health workers. The more recent mWELLCARE $\operatorname{tria}^{55}$ was a large, well-designed study in India designed to use a mHealth system for integrated management of five chronic condition including hypertension. However, the study did not find a significant reduction in blood pressure. Other studies such as the STAR (SMS Text-message Adherence suppoRt) trial among hypertensive patients ${ }^{43}$ and the
Text2 preventCVD study ${ }^{56}$ have reported promising findings with an intervention that uses text messages. Given this background, we undertook this formative research to develop a mHealth strategy based on participant and stake holder input. We recommend that research in the application of mHealth needs to be undertaken in the future to align the mHealth strategy to the culture and context of the existing healthcare system to increase the likelihood of adoption of such interventions.

\section{Strengths and limitations of the study}

One of the strengths of the study is that efforts were taken to ensure the trustworthiness ${ }^{37}$ of data by ensuring credibility, through appropriate and different methods for data collection (IDIs and FGDs); by including a different cadre of participants (patients, their family, health workers, KI) from different sites (primary and tertiary level). The researcher $(\mathrm{BB})$ obtained participant validation at the end of the interview by summarising the main points to ensure the respondent's perspective. ${ }^{57}$ In addition, we have used the TAM model to inform our analysis. Some limitations of this study were that we analysed data from different sources and methods together, which might not fulfil all the criteria of triangulation. This study also used purposive sampling to identify participants, which may have created a selection bias. However, all reasonable efforts were made to ensure the diversity of participants. Furthermore, the transferability of the findings is limited as this study was conducted in urban and semiurban parts of the country, which may not completely represent the views of people from geographically-disadvantaged and remote areas of LMICs.

\section{CONCLUSIONS}

This study found that participants were receptive towards a simple mHealth strategy for controlling hypertension using SMS notifications. Overall, there was a consensus on the value of a text messaging solution to hypertension management by all stakeholder groups. However, meticulous planning is required to include a diverse range of participants to ensure the text messaging strategy is acceptable to a wide range of participants, including illiterate and older groups. Similar formative study approaches can be used to inform contextual design of mHealth in other LMIC settings.

\section{Author affiliations}

${ }^{1}$ School of Population Health, University of New South Wales, Sydney, New South Wales, Australia

${ }^{2}$ Central Department of Public Health, Tribhuvan University Institute of Medicine, Kathmandu, Nepal

${ }^{3}$ Cardiovascular Division, The George Institute for Global Health, Sydney, New South Wales, Australia

${ }^{4}$ Community Medicine, Kathmandu Medical College, Kathmandu, Nepal

${ }^{5}$ School of Public Health, Patan Academy of Health Sciences, Kathmandu, Nepal

Twitter Buna Bhandari @bunabh, Aletta E Schutte @alta_schutte and Padmanesan Narasimhan @padmanesan 
Acknowledgements BB received the Australia Awards Scholarship to PhD funded by the Department of Foreign Affairs and Trade Australia, without which this study would not have been possible. The authors acknowledge the local authorities of Kageswori Manahara Municipality of Kathmandu, Nepal and the Kathmandu Medical College and Teaching Hospital for supporting the fieldwork. We would like to express our sincere appreciation to all the participants for taking part in this study. We would like to extend special thanks to the research assistants (Pratima Karki and Alpha Pokharel) who helped to transcribe the recordings of IDIs.

Contributors All authors contributed to the conception of research design, acquisition, and data interpretation. BB conducted the fieldwork and wrote the first version of this manuscript. BB and PN participated in the analysis of the data. All the authors were involved in the manuscript drafting, revision, and finalisation. All authors read and approved the final version of the manuscript.The guarantors (BB,PN,AES) accepts full responsibility for the work and/or the conduct of the study, had access to the data, and controlled the decision to publish.

Funding The authors have not declared a specific grant for this research from any funding agency in the public, commercial or not-for-profit sectors.

Competing interests None declared.

Patient consent for publication Consent obtained directly from patient(s)

Ethics approval Ethics approval for the study was obtained from the Human Research Ethics Committee of the University of New South Wales, Australia (Ref no: HC17753) and Nepal Health Research Council (Ref no 21/2018). Informed consent was taken from all the study participants.

Provenance and peer review Not commissioned; externally peer reviewed.

Data availability statement Data are available upon reasonable request. The data for this research consists of audio recordings of interviews, interview transcripts. The researchers have access to these data. All data are stored securely on password-protected and encrypted computers. Participants have not given their permission for data sharing outside the research group. Thus, no additional data are available.

Supplemental material This content has been supplied by the author(s). It has not been vetted by BMJ Publishing Group Limited (BMJ) and may not have been peer-reviewed. Any opinions or recommendations discussed are solely those of the author(s) and are not endorsed by BMJ. BMJ disclaims all liability and responsibility arising from any reliance placed on the content. Where the content includes any translated material, BMJ does not warrant the accuracy and reliability of the translations (including but not limited to local regulations, clinical guidelines, terminology, drug names and drug dosages), and is not responsible for any error and/or omissions arising from translation and adaptation or otherwise.

Open access This is an open access article distributed in accordance with the Creative Commons Attribution Non Commercial (CC BY-NC 4.0) license, which permits others to distribute, remix, adapt, build upon this work non-commercially, and license their derivative works on different terms, provided the original work is properly cited, appropriate credit is given, any changes made indicated, and the use is non-commercial. See: http://creativecommons.org/licenses/by-nc/4.0/.

\section{ORCID iDs}

Buna Bhandari http://orcid.org/0000-0002-0102-8844

Aletta E Schutte http://orcid.org/0000-0001-9217-4937

Rohan Jayasuriya http://orcid.org/0000-0003-3108-2304

Abhinav Vaidya http://orcid.org/0000-0001-5523-3459

\section{REFERENCES}

1 Mills KT, Bundy JD, Kelly TN, et al. Global disparities of hypertension prevalence and control: a systematic analysis of population-based studies from 90 countries. Circulation 2016;134:441-50.

2 Schutte AE, Srinivasapura Venkateshmurthy N, Mohan S, et al. Hypertension in low- and middle-income countries. Circ Res 2021:128:808-26.

3 Chow CK, Teo KK, Rangarajan S, et al. Prevalence, awareness, treatment, and control of hypertension in rural and urban communities in high-, middle-, and low-income countries. JAMA 2013;310:959-68.

4 Haider MR, Das Gupta R. Inequalities in undiagnosed hypertension among adult Nepalese population: evidence from a nationally representative survey. Int J Cardiol Hypertens 2020;5:100026.

5 Dhungana RR, Pandey AR, Shrestha N. Trends in the prevalence, awareness, treatment, and control of hypertension in Nepal between
2000 and 2025: a systematic review and meta-analysis. Int J Hypertens 2021;2021:1-11.

6 Bhandari B, Bhattarai M, Bhandari M. Adherence to antihypertensive medications: population based follow up in eastern Nepal. J Nepal Health Res Counc 2015;13:38-42.

7 NHRC, MoHP, MEOR. Burden of disease 2017: a country report based on the global burden of disease 2017 study. Kathmandu, Nepal. Nepal health research Council (NHRC), Ministry of health and population (MoHP) and monitoring evaluation and operational research (MEOR. Nepal, 2019.

8 Roth GA, Mensah GA, Johnson CO, et al. Global burden of cardiovascular diseases and risk factors, 1990-2019: update from the GBD 2019 study. J Am Coll Cardiol 2020;76:2982-3021.

9 Halme L, Vesalainen R, Kaaja M, et al. Self-Monitoring of blood pressure promotes achievement of blood pressure target in primary health care. Am J Hypertens 2005;18:1415-20.

10 Lu C-H, Tang S-T, Lei Y-X, et al. Community-Based interventions in hypertensive patients: a comparison of three health education strategies. BMC Public Health 2015;15:33.

11 Hennessy S, Leonard CE, Yang W, et al. Effectiveness of a two-part educational intervention to improve hypertension control: a clusterrandomized trial. Pharmacotherapy 2006;26:1342-7.

12 Glynn LG, Murphy AW, Smith SM, et al. Interventions used to improve control of blood pressure in patients with hypertension. Cochrane Database Syst Rev 2010:CD005182.

13 Bhandari B, Narasimhan P, Vaidya A, et al. Barriers and facilitators for treatment and control of high blood pressure among hypertensive patients in Kathmandu, Nepal: a qualitative study informed by COM-B model of behavior change. BMC Public Health 2021;21:1524.

14 Khatib R, Schwalm J-D, Yusuf S, et al. Patient and healthcare provider barriers to hypertension awareness, treatment and follow up: a systematic review and meta-analysis of qualitative and quantitative studies. PLoS One 2014;9:e84238.

15 World Health Organisation. mHealth: new horizons for health through mobile technologies: second global survey on eHealth. Geneva: World Health Organization, 2011.

16 Beratarrechea A, Lee AG, Willner JM, et al. The impact of mobile health interventions on chronic disease outcomes in developing countries: a systematic review. Telemed J E Health 2014;20:75-82.

17 Aranda-Jan CB, Mohutsiwa-Dibe N, Loukanova S. Systematic review on what works, what does not work and why of implementation of mobile health (mHealth) projects in Africa. BMC Public Health 2014;14:188.

18 Peiris D, Praveen D, Johnson C, et al. Use of mHealth systems and tools for non-communicable diseases in low- and middleincome countries: a systematic review. J Cardiovasc Transl Res 2014;7:677-91.

19 Rehman H, Kamal AK, Morris PB, et al. Mobile health (mHealth) technology for the management of hypertension and hyperlipidemia: slow start but loads of potential. Curr Atheroscler Rep 2017;19:12.

20 Priyaa S, Murthy S, Sharan S, et al. A pilot study to assess perceptions of using SMS as a medium for health information in a rural setting. Technol Health Care 2014;22:1-11.

21 Suffoletto B. Text message behavioral interventions: from here to where? Curr Opin Psychol 2016;9:16-21.

22 Nepal Telecommunications Authrority. The management information system (mis. Nepal Telecommunications Authority, 2021.

23 Acharya A, Cunningham K, Manandhar S, et al. Exploring the use of mobile health to improve community-based health and nutrition service utilization in the hills of Nepal: qualitative study. J Med Internet Res 2020;22:e17659.

24 Bhatta R. Telemedicine and e-health in Nepal. Journal of Nepal Public Health Association 2015;6:41-6.

$25 \mathrm{Ni} \mathrm{Z}$, Atluri N, Shaw RJ, et al. Evaluating the feasibility and acceptability of a mobile Health-Based female community health volunteer program for hypertension control in rural Nepal: crosssectional study. JMIR Mhealth Uhealth 2020;8:e15419.

26 Smith R, Menon J, Rajeev JG, et al. Potential for the use of mHealth in the management of cardiovascular disease in Kerala: a qualitative study. BMJ Open 2015;5:e009367.

27 Davis FD. Perceived usefulness, perceived ease of use, and user acceptance of information technology. MIS Quarterly 1989;13:319-40.

28 Szajna B. Empirical evaluation of the revised technology acceptance model. Manage Sci 1996;42:85-92.

29 King WR, He J. A meta-analysis of the technology acceptance model. Inf Manag 2006;43:740-55.

30 Nguyen M, Fujioka J, Wentlandt K, et al. Using the technology acceptance model to explore health provider and administrator 
perceptions of the usefulness and ease of using technology in palliative care. BMC Palliat Care 2020;19:1-9.

31 Rahimi B, Nadri H, Lotfnezhad Afshar $\mathrm{H}$, et al. A systematic review of the technology acceptance model in health informatics. Appl Clin Inform 2018;9:604-34.

32 Chang LW, Njie-Carr V, Kalenge S, et al. Perceptions and acceptability of mHealth interventions for improving patient care at a community-based HIV/AIDS clinic in Uganda: a mixed methods study. AIDS Care 2013;25:874-80.

33 Carter N, Bryant-Lukosius D, DiCenso A, et al. The use of triangulation in qualitative research. Oncol Nurs Forum 2014;41:545-7.

34 Fontana A, Frey JH. The Interview, From Structured Questions to Negotiated Text" i Handbook of Qualitative Research, Denzin, Norman K., \& Lincoln Yvonna S.,(red. Thousand Oaks: Sage Publications, Inc., 2000.

35 Morgan DL. Focus groups. Annu Rev Sociol 1996;22:129-52.

36 O.Nyumba T, Wilson K, Derrick CJ, et al. The use of focus group discussion methodology: insights from two decades of application in conservation. Methods Ecol Evol 2018;9:20-32.

37 Shenton AK. Strategies for ensuring trustworthiness in qualitative research projects. EFI 2004;22:63-75.

38 QSR International. NVivo qualitative data analysis software, 1999. Available: https://qsrinternational.com/nvivo/nvivo-products/

39 Braun V, Clarke V. Using thematic analysis in psychology. Qual Res Psychol 2006;3:77-101.

40 Tong A, Sainsbury P, Craig J. Consolidated criteria for reporting qualitative research (COREQ): a 32-item checklist for interviews and focus groups. Int J Qual Health Care 2007;19:349-57.

41 DeSouza SI, Rashmi MR, Vasanthi AP, et al. Mobile phones: the next step towards healthcare delivery in rural India? PLoS One 2014;9:e104895

42 Thakkar J, Kurup R, Laba T-L, et al. Mobile telephone text messaging for medication adherence in chronic disease: a meta-analysis. JAMA Intern Med 2016;176:340-9.

43 Bobrow K, Farmer AJ, Springer D, et al. Mobile Phone Text Messages to Support Treatment Adherence in Adults With High Blood Pressure (SMS-Text Adherence Support [StAR]): A SingleBlind, Randomized Trial. Circulation 2016;133:592-600.

44 Sidney K, Antony J, Rodrigues R, et al. Supporting patient adherence to antiretrovirals using mobile phone reminders: patient responses from South India. AIDS Care 2012;24:612-7.
45 Times TH. Illiteracy, old policies hurdles for Digital Nepal. The Himalaya Times, 2019. Available: https://thehimalayantimes.com/ business/illiteracy-old-policies-hurdles-for-digital-nepal

46 Lall D, Engel N, Devadasan N, et al. Challenges in primary care for diabetes and hypertension: an observational study of the Kolar district in rural India. BMC Health Serv Res 2019;19:44.

47 Kariuki EG, Okanda P, eds. Adoption of $m$-health and usability challenges in m-health applications in Kenya: Case of Uzazi Poa mhealth prototype application. 2017 IEEE AFRICON; 2017: IEEE.

48 Islam MN, Karim MM, Inan TT, et al. Investigating usability of mobile health applications in Bangladesh. BMC Med Inform Decis Mak 2020;20:19

49 Becker S, Miron-Shatz T, Schumacher N, et al. mHealth 2.0: experiences, possibilities, and perspectives. JMIR Mhealth Uhealth 2014;2:e24.

50 Albright K, Krantz MJ, Backlund Jarquín P, et al. Health promotion text messaging preferences and acceptability among the medically underserved. Health Promot Pract 2015;16:523-32.

51 Davey S, Davey A, Singh JV. Mobile-health approach: a critical look on its capacity to augment health system of developing countries. Indian J Community Med 2014;39:178.

52 Bhandari B, Narasimhan P, Vaidya A, et al. Theory-based mobile phone text messaging intervention for blood pressure control (TEXT4BP) among hypertensive patients in Nepal: study protocol for a feasibility randomised controlled trial. BMJ Open 2020;10:e040799.

53 GoN, MoHP. Nepal health sector strategy 2015-2020. Government of Nepal; Ministry of Health and Population, 2015: 5-20.

54 Jafar TH, Gandhi M, de Silva HA, et al. A community-based intervention for managing hypertension in rural South Asia. $N$ Engl $J$ Med 2020;382:717-26.

55 Prabhakaran D, Jha D, Prieto-Merino D, et al. Effectiveness of an $\mathrm{mHealth}$-based electronic decision support system for integrated management of chronic conditions in primary care: the mWellcare cluster-randomized controlled trial. Circulation 2018. doi:10.1161/ CIRCULATIONAHA.118.038192. [Epub ahead of print: 10 Nov 2018].

56 Shariful Islam SM, Farmer AJ, Bobrow K, et al. Mobile phone textmessaging interventions aimed to prevent cardiovascular diseases (Text2PreventCVD): systematic review and individual patient data meta-analysis. Open Heart 2019;6:e001017.

57 Meyrick J. What is good qualitative research? a first step towards a comprehensive approach to judging rigour/quality. J Health Psychol 2006;11:799-808. 